\title{
COMPARAÇÃO DO MÓDULO FLEXURAL DE PINOS ESTÉTICOS.
}

Gislaine Cristine MARTINS, Ana Paula Gebert de Oliveira FRANCO, Roberta NOVAES, Eloisa de Paula GODOY, Mildred HECKE

O objetivo desse estudo foi comparar os valores do módulo flexural de 5 tipos de pinos intra-radiculares estéticos. Para a investigação foram selecionados 50 pinos divididos em 5 grupos ( $n=10$ ): G1: Exacto (Angelus $\left.{ }^{\circledR}\right)$ de fibra de vidro com filamento metálico, G2: Reforpost RX (Angelus $\AA$ ) fibra de vidro com filamento metálico, G3: Reforpost RX MIX (Angelus $\left({ }^{\circledR}\right)$ fibra de carbono revestido com fibra de vidro e filamento metálico, G4: White DC Post (FGM®) em fibras de vidro translúcido e G5: Superpost Glass (Superdont $₫$ ) em fibras de vidro. Os espécimes foram submetidos ao ensaio de resistência flexural de 3 pontos em uma Máquina Universal de Ensaios AG-I Shimadzu a uma velocidade de $0,5 \mathrm{~mm} / \mathrm{min}$. Os dados foram analisados por meio de estatística descritiva onde os valores médios e desvio padrão em GPa foram: G1: $85,82 \pm 4,97$; G2: 100,25 $\pm 6,70 ;$ G3: 90,59 $\pm 39,24 ;$ G4: $67,55 \pm 12,61 ;$ G5: $36,44 \pm 5,38$. Os resultados analisados pelo teste ANOVA e Bonferroni com $\alpha=0.05$ demonstraram diferenças estatisticamente significantes entre os grupos (1 e 5), (2 e 4), (2 e 5), (3 e 4), (3 e 5) e (4 e 5). Concluiu-se que os pinos com filamentos metálicos (G1, G2 e G3) apresentaram valores de módulo flexural maiores em relação aos demais pinos. 